\title{
Violência sexual contra crianças: autores, vítimas e consequências
}

\author{
Sexual violence against children: authors, victims and consequences
}

\author{
Vanessa Borges Platt ${ }^{1}$ \\ Isabela de Carlos Back ${ }^{1}$ \\ Daniela Barbieri Hauschild ${ }^{2}$ \\ Jucélia Maria Guedert ${ }^{3}$
}

${ }^{1}$ Programa de PósGraduação em Saúde Coletiva, Departamento de Saúde Coletiva, Centro de Ciências da Saúde, Universidade Federal de Santa Catarina (UFSC). Hospital Universitário Trindade. 88040-970 Florianópolis SC Brasil. vanessa.platt@ufsc.br ${ }^{2}$ Programa de Pós-

Graduação em Nutrição, Departamento de Nutrição, Centro de Ciências da Saúde, UFSC.

${ }^{3}$ Hospital Infantil Joana

de Gusmão, Hospital Universitário, UFSC. Florianópolis SC Brasil.
Abstract The scope of this study was to identify the characteristics of sexual abuse against children including the profiles of the victims and the perpetrators, and associated factors notified in a health service of reference with the database of the Brazilian Case Registry Database, in a city in the south of Brazil. Categorical variables are presented in prevalence with 95\% confidence intervals. There were 489 notifications from 2008 to 2014 of confirmed or suspected child sexual abuse. The majority was related to female victims, but the repeated abuse was reported mainly with male victims. In most cases, the abuse took place at the victims' or perpetrators' homes and the main perpetrators of abuse were male and acquainted with the victims. Twelve victims have contracted sexually transmitted infections; pregnancies were six, five of them legally terminated. This study highlights that the child sexual abuse profiles were similar in almost all of Brazilian regions, showing that it is possible to have a coordinated national action to prevent this offence.

Key words Sexual violence, Children
Resumo O objetivo deste estudo foi identificar características do abuso sexual contra crianças, como perfil da vítima, do autor da agressão e fatores associados, notificadas em um serviço de referência, utilizando o Sistema de Informação de Agravos de Notificação, em todos os casos suspeitos ou confirmados de abuso sexual infantil, de 2008 a 2014, em Florianópolis/SC. As variáveis foram: características da vitima, do agressor, da ocorrência, tipologia da violência, consequências, encaminhamentos e procedimentos realizados. Variáveis categóricas são apresentadas em prevalências e intervalos de confiança de 95\%. Houve 489 notificações, predominando vítimas do sexo feminino, maior recorrência no masculino e ocorrendo em residências. Estupro foi duas vezes mais frequente no sexo feminino e em mais da metade dos casos o autor era homem conhecido da vítima. Doze vítimas contraíram infecções sexualmente transmissíveis, houve seis gestações, cinco delas interrompidas legalmente. Mesmo sendo inédito para a região estudada, se observou características semelhantes às encontradas em outros estudos brasileiros, mostrando ser possivel ações coordenadas nacionalmente para prevenir esse agravo. Palavras-chave Violência sexual, Crianças 


\section{Introdução}

Segundo a Organização Mundial da Saúde (OMS), toda criança tem direito à saúde e à vida longe da violência. Abuso sexual infantil (ASI) ocorre quando uma criança é submetida à atividade sexual a qual não possa compreender, com a qual ela tem o desenvolvimento incompatível, e que não possa dar consentimento e/ou que viole as leis ou as regras da sociedade ${ }^{1}$.

Ainda que os resultados sejam claros em mostrar que a experiência em ASI é altamente prevalente em todas as sociedades investigadas, uma metanálise com estudos internacionais estimou uma prevalência média de ASI de 20,0\% para mulheres e $8,0 \%$ para homens ${ }^{2}$. As variações nessas taxas provavelmente decorrem das diferentes definições de ASI, no que concerne à faixa etária e às diferenças metodológicas existentes entre os estudos $^{3}$. Nos países nórdicos as taxas variaram de $14,0 \%$ para mulheres e $7,0 \%$ para homens, na Dinamarca; 2,4 a 9,3\% para as mulheres e de 0,7 a 4,6\% para os homens, na Finlândia; na Suécia, a prevalência global variou de 2,0 a $11,0 \%$ e, na Noruega, de 10,0\%4.

Estudos brasileiros ${ }^{5-8}$ evidenciam que a maioria de casos de abuso sexual ocorrem em meninas entre 5 e 10 anos. Os meninos também são abusados, porém em menor proporção, principalmente quando o abuso é intrafamiliar ${ }^{1}$. Um estudo realizado no estado de Santa Catarina (SC), em 2005, com dados obtidos de registros de notificações do Conselho Tutelar e Programa Sentinela do município de Itajaí, no período de 1999 a 2003, mostrou que grande parte das violências sexuais em crianças e adolescentes ocorreram dentro de casa, tendo o pai como autor ${ }^{8}$.

O ASI é considerado importante fator de risco para vários problemas de saúde na infância e na vida adulta ${ }^{1,9,10}$, que impactam sobremaneira a saúde física e principalmente psicológica das vítimas. Demanda também ônus substancial ao sistema de saúde (consultas médicas e internações hospitalares $)^{1,10-18}$.

Estimar a prevalência de ASI é fundamental para determinar a extensão do problema e possíveis intervenções, sendo a organização da notificação desse agravo imprescindível para uma atenção integral às pessoas em situação de violência ${ }^{19}$. Devido à inclusão relativamente recente (2008) dos dados referentes à violência sexual no Sistema de Informação de Agravos de Notificação (SINAN), como via de universalização da vigilância contínua, utilizá-lo de forma sistemática é a melhor forma de avaliá-lo e melhorá-lo.
O objetivo deste estudo foi identificar características do abuso sexual infantil, tais como perfil da vítima e do autor da agressão e fatores associados à violência sexual, notificados em um serviço de referência desse agravo, utilizando registros do SINAN.

\section{Método}

Estudo transversal, descritivo e analítico, com dados secundários do SINAN. Nele se analisaram todos os casos suspeitos ou confirmados de abuso sexual infantil, no período de janeiro de 2008 a dezembro de 2014, notificados por um hospital pediátrico de Florianópolis, Santa Catarina.

O local onde esta pesquisa foi desenvolvida é referência regional no atendimento de crianças e adolescentes vítimas ASI desde 2000, fazendo parte do "Protocolo de Atenção às Vítimas de Violência Sexual do Município de Florianópolis". Fornece dados ao SINAN com notificações de qualquer caso suspeito ou confirmado de violência doméstica, sexual e/ou outras violências contra crianças e adolescentes, em conformidade com o instrutivo da ficha de notificação.

As informações de interesse neste estudo foram obtidas a partir da ficha de registro preenchida pelo profissional responsável pelo atendimento. As variáveis descritas foram categorizadas de acordo com o "Instrutivo de notificação de violência doméstica, sexual e outras violências" do Ministério da Saúde ${ }^{19}$, em dados relacionados à vítima, à ocorrência, à tipologia da violência sexual, às consequências, ao provável agressor, aos encaminhamentos e aos procedimentos realizados com as vítimas.

Com relação à vítima, foram considerados: idade, raça ou cor, presença ou não de deficiências ou transtorno, e local de residência. A idade foi registrada em anos completos no momento da notificação e categorizada, conforme Marcondes et $a^{20}{ }^{20}$, nas seguintes faixas etárias: 0 a 2 anos (exclusive), 3 a 6 (exclusive), 6 a 10 anos (exclusive) e 10 a 15 (exclusive). A raça ou cor registrada seguiu autorreferência da vítima/informante conforme as opções utilizadas no Censo de 2010, do Instituto Brasileiro de Geografia e Estatística (IBGE): branca, preta, amarela, parda ou indígena ${ }^{21}$. As deficiências ou transtornos foram classificados em visual, auditivo, mental, físico e comportamental. Eles foram agrupados, gerando a variável "deficiência”, que foi dicotomizada em presença ou ausência. O local de residência considerou município e respectiva Unidade Federativa (UF) ${ }^{22}$. 
Quanto à ocorrência, foram investigados: município e respectiva UF; situação urbana (zona urbana, rural ou periurbana); natureza do local onde ocorreu o abuso (residência, habitação coletiva, escola, local da prática esportiva, bar ou similar, via pública, comércio ou serviços, indústrias ou construção); e número de vezes em que a vítima foi abusada (categorizado em "uma vez" ou "duas ou mais vezes"). Os locais de residência e habitação coletiva, que segundo o instrutivo, para a faixa etária pediátrica, inclui barracão (acampamento de trabalhadores), casa de estudantes (república), caserna, hospital psiquiátrico (quando utilizado como moradia pela pessoa atendida/vítima), instituição de acolhimento (abrigo), hospitais colônias, pensionato, unidade socioeducativa, unidade de acolhimento, albergue; foram agrupados, gerando a variável "residência" e os demais locais foram agrupados na variável "qualquer outro lugar".

A violência sexual foi tipificada em termos da presença ou ausência de assédio sexual, atentado violento ao pudor e estupro.

Também foi objeto de análise a ocorrência ou não de penetração. Em caso afirmativo, determinou-se qual o tipo: se anal, oral ou vaginal. Mesmo com a Lei Federal Brasileira no ${ }^{\circ} 12.015$ de $2009^{23,24}$, fundindo em um único artigo os crimes de estupro e atentado violento ao pudor, optouse por analisar os dois conceitos separados e de forma conjunta, pois a ficha manteve a categorização inalterada até o ano de 2015. A legislação acima citada, definia Atentado Violento ao Pudor como "constranger alguém, mediante violência ou grave ameaça, a praticar ou permitir que com ele se pratique ato libidinoso diverso da conjunção carnal" e, estupro como sendo "constranger mulher à conjunção carnal, mediante violência ou grave ameaça”.

Os procedimentos indicados quando da notificação foram listados, conforme a necessidade da realização de profilaxia para infecções sexualmente transmissíveis (ISTs), vírus da imunodeficiência humana (HIV), Hepatite B ou Tétano. Descreveu-se a necessidade ou não de coleta de sangue, de sêmen, de secreção vaginal e de realização da contracepção de emergência ou aborto previsto em lei. Das consequências da ocorrência detectadas no momento da notificação, foi investigada a presença de aborto, gravidez, IST, tentativa de suicídio, transtorno mental ou do comportamento e Transtorno do Estresse PósTraumático (TEPT).

Caracterizou-se o provável autor da violência sexual quanto ao sexo, número de envolvidos, suspeita do uso de álcool (se sim ou não) e vínculo/grau de parentesco com a vítima (se pai, mãe, padrasto, madrasta, cônjuge, ex-cônjuge, namorado, ex-namorado, irmão, amigo, cuidador, desconhecido, pessoa em relação institucional ou outros). Esta última variável foi analisada separadamente e também de forma agrupada, gerando a variável "conhecido". Neste grupo, "ser conhecido da vítima" foi composto pelos "autores": pai, mãe, padrasto, madrasta, cônjuge, ex-cônjuge, namorado, ex-namorado, irmão, amigos, cuidador, amigo, pessoa em relação institucional e outros.

Também foi investigado para onde a vítima foi encaminhada: Conselho Tutelar, Vara da Infância e Juventude, Casa Abrigo, Programa Sentinela, Delegacia de Proteção da Criança e do Adolescente, Ministério Público ou Instituto Médico Legal (IML).

Os dados obtidos foram exportados do SINAN no formato Excel, avaliados separadamente por três observadores e, quando havia dúvidas ou discordância nos mesmos, realizada a conferência na própria ficha de notificação. Posteriormente esses dados foram analisados utilizando o software estatístico Stata 11.0.

As variáveis categóricas são apresentadas com as prevalências e os respectivos intervalos de confiança de 95\% (IC: 95\%). Para determinação das diferenças das diversas variáveis entre os sexos, foi realizado o teste de qui-quadrado.

O projeto deste estudo foi aprovado pelo Comitê de Ética em Pesquisa em Seres Humanos do Hospital Infantil Joana de Gusmão. Foram respeitados os princípios de ética na pesquisa com seres humanos presentes nas resoluções do Conselho Nacional de Saúde.

\section{Resultados}

No período de janeiro de 2008 a dezembro de 2014 foram feitas 490 notificações de casos suspeitos ou confirmados de ASI. Uma notificação estava em duplicidade e foi excluída. Dez casos possuíam duas notificações em datas diferentes e um possuía três notificações distintas. Dessa forma, a amostra final foi composta pelos dados de 477 crianças e adolescentes.

A distribuição do número de notificações ao longo dos sete anos pode ser observada na Figura 1.

A maioria das vítimas era do sexo feminino (75,5\%), branca $(78,0 \%)$ e não possuía deficiência $(94,5 \%)$. Uma notificação correspondeu a uma vítima de raça indígena. A faixa etária mais aco- 


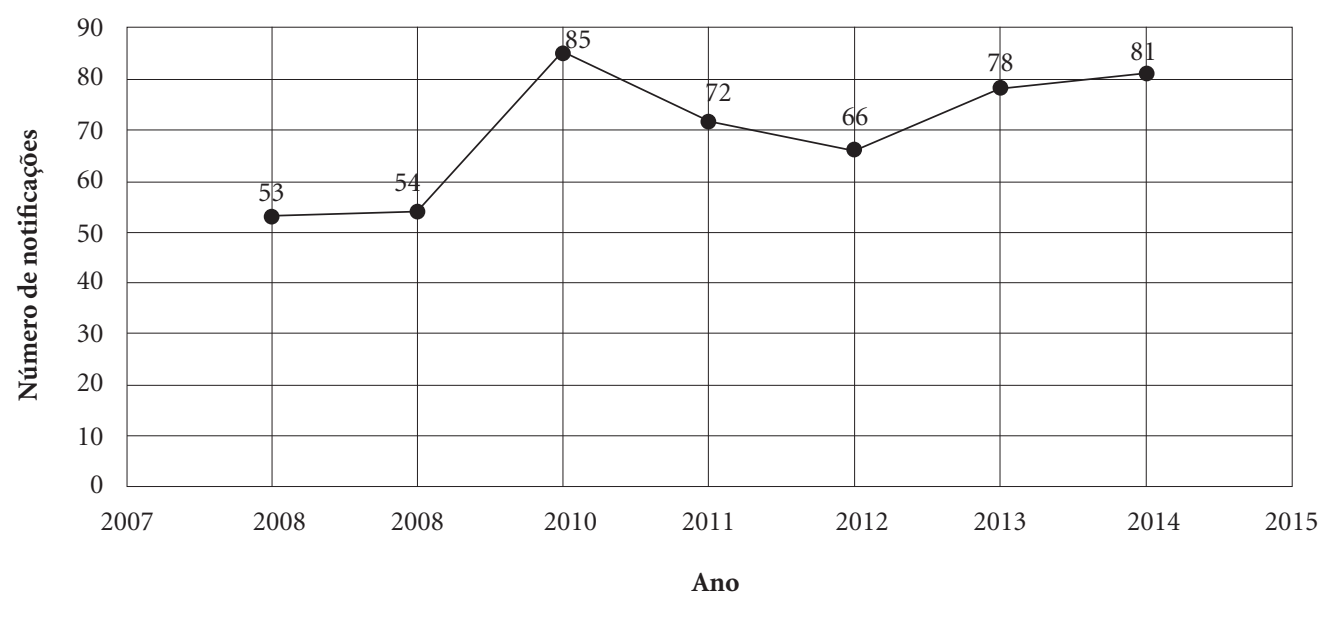

Figura 1. Número de notificações/ano de ASI $(n=489)$ do HIJG (SINAN), SC, 2008 - 2014.

Nota: ASI: abuso sexual infantil. HIJG: Hospital Infantil Joana de Gusmão. SINAN: Sistema de Informação de Agravos de Notificação.

metida no sexo feminino foi a de 10 a 15 anos $(41,2 \%)$; no masculino, de 2 a 6 anos $(42,5 \%)$. Quando a amostra foi estratificada em crianças e adolescentes, segundo o Estatuto da Criança e do Adolescente (ECA), observou-se a prevalência de ASI mais frequentemente nos menores de 12 anos $(67,7 \%)$ (Tabela 1$)$.

Entre os municípios de ocorrência, Florianópolis apresentou o maior número das notificações, com $57,9 \%$ dos casos. O perímetro urbano foi a zona mais citada $(98,5 \%)$, sendo a residência da vítima ou do autor o local mais frequente da prática do abuso $(81,6 \%)$, em ambos os sexos. As vítimas procederam de 25 diferentes municípios de Santa Catarina e de 2 do Rio Grande do Sul.

Quanto às características dos autores do ASI, $66,5 \%\left(\mathrm{IC}_{95 \%} 62,3-70,7\right)$ eram conhecidos das vítimas; predominantemente do sexo masculino 91,9\% ( IC $\left._{95 \%} 89,3-94,4\right)$; não haviam consumido álcool quando do abuso 68,6\% ( IC $\left._{95 \%} 63,1-74,0\right)$; e agiram sozinhos $85,2 \%\left(\mathrm{IC}_{95 \%}, 81,9-88,6\right)$. A variável ser conhecido da vítima apareceu mais frequentemente como autor em ambos os sexos (Tabela 2).

Como demonstrado na Tabela 3, optou-se por analisar os tipos de abuso separadamente, conforme descrição da ficha de notificação, e de forma conjunta, em consonância com a legislação vigente ${ }^{23}$. Atentado violento ao pudor foi o abuso mais observado nas vítimas do sexo mas- culino, enquanto o estupro foi mais de três vezes mais frequente no sexo feminino. Quando associados os tipos de violência "atentado violento ao pudor e estupro", categorizados agora como "estupro" de acordo com a definição legal atual, observou-se que ele foi duas vezes mais frequente nas vítimas do sexo feminino. Quando o abuso foi acompanhado de penetração, anal ou oral, as vítimas do sexo masculino foram as mais acometidas. A penetração vaginal ocorreu em 59\% dos casos $\left(\mathrm{IC}_{95 \%,}\right.$ 52,4-65,6).

Quanto aos procedimentos realizados, referidos no momento da notificação, observou-se que a maioria das vítimas não fez profilaxia para IST $(71,7 \%)$, para HIV $(72,9 \%)$ ou para Hepatite B $(78,6 \%)$. Não houve coleta de sêmen em 89,2\% dos casos e de secreção vaginal em $75,4 \%$. No período de tempo analisado, cinco adolescentes $\left(3,5 \%, \mathrm{IC}_{95 \%} 0,4-6,5\right)$ foram encaminhadas para a interrupção legal da gestação e 48 (16,7 \%, IC 93,5-99,6) fizeram uso da medicação utilizada para contracepção de emergência. Houve um caso de gravidez $(1,0 \%)$ que foi levada a termo, e doze casos de ISTs $(3,4 \%)$, decorrentes do abuso. Esses dados quando analisados por sexo, não mostraram diferença estatisticamente significante (Tabela 4).

Dentre as consequências imediatas, destacase o impacto do ASI sobre a saúde mental das vítimas, pois quatro $(1,0 \%)$ destas tentaram sui- 
Tabela 1. Caracterização das vítimas de ASI $(n=489)$, segundo o sexo, notificados pelo HIJG (SINAN), SC, 2008 -2014 .

\begin{tabular}{|c|c|c|c|c|c|}
\hline \multirow{2}{*}{ Variáveis } & \multicolumn{2}{|c|}{ Feminino } & \multicolumn{2}{|c|}{ Masculino } & \multirow[t]{2}{*}{ p-valor ${ }^{\mathrm{a}}$} \\
\hline & n (\%) & IC95\% & n (\%) & IC95\% & \\
\hline $\mathrm{n}$ & $369(100,0)$ & - & $120(100,0)$ & - & \\
\hline \multicolumn{6}{|l|}{ Idade $^{\dagger}$} \\
\hline$<2$ anos & $21(5,7)$ & $3,3-8,1$ & $9(7,5)$ & $2,7-12,3$ & $<0,001$ \\
\hline 2 |-- 6anos & $115(31,2)$ & $26,5-26,3$ & $51(42,5)$ & $33,5-51,5$ & \\
\hline $6 \mid--10$ anos & $81(21,9)$ & $17,8-26,3$ & $37(30,8)$ & $22,5-39,2$ & \\
\hline $10 \mid--15$ anos & $152(41,2)$ & $36,1-46,2$ & $23(19,2)$ & $12,0-26,3$ & \\
\hline \multicolumn{6}{|l|}{ Idade ECA } \\
\hline Criança & $225(69,1)$ & $64,6-74,0$ & $106(88,3)$ & $82,5-94,2$ & $<0,001$ \\
\hline Adolescente & $114(30,9)$ & $26,2-35,6$ & $14(11,7)$ & $5,8-17,5$ & \\
\hline \multicolumn{6}{|l|}{ Cor/Raça* } \\
\hline Branca & $251(77,5)$ & $72,9-82,0$ & $82(79,6)$ & $71,7-87,5$ & NA \\
\hline Preta & $27(8,3)$ & $5,3-11,4$ & $9(8,7)$ & $3,2-14,3$ & \\
\hline Amarela & $1(0,3)$ & $0,0-0,9$ & $1(1,0)$ & $0,0-2,9$ & \\
\hline Parda & $44(13,6)$ & $9,8-17,8$ & $11(10,7)$ & $4,6-16,7$ & \\
\hline Indígena & $1(0,3)$ & $0,0-0,9$ & - & - & \\
\hline \multicolumn{6}{|l|}{ Deficiência } \\
\hline Não & $349(94,6)$ & $92,3-96,9$ & $113(94,2)$ & $89,9-98,4$ & 0,863 \\
\hline Sim & $20(5,4)$ & $3,1-7,7$ & $7(5,8)$ & $1,6-10,1$ & \\
\hline \multicolumn{6}{|l|}{ Ocorrência* } \\
\hline $1 \mathrm{vez}$ & $137(51,3)$ & $45,3-57,3$ & $33(41,3)$ & $30,2-52,3$ & 0,114 \\
\hline 2 ou mais & $130(48,7)$ & $42,7-54,7$ & $47(58,8)$ & $47,7-69,8$ & \\
\hline
\end{tabular}

Tabela 2. Caracterização dos autores $(n=444)$ de ASI, segundo sexo da vítima, notificados pelo HIJG (SINAN), SC, $2008-2014$.

\begin{tabular}{|c|c|c|c|c|c|}
\hline \multirow{2}{*}{ Variáveis } & \multicolumn{2}{|c|}{ Feminino } & \multicolumn{2}{|c|}{ Masculino } & \multirow[t]{2}{*}{ p-valor } \\
\hline & n (\%) & IC95\% & n (\%) & IC95\% & \\
\hline $\mathrm{n}$ & $369(100,0)$ & - & $120(100,0)$ & - & \\
\hline \multicolumn{6}{|l|}{$\operatorname{Sexo}^{*}$} \\
\hline Masculino & $313(92,8)$ & $90,1-95,6$ & $95(88,8)$ & $83,9-95,6$ & 0,382 \\
\hline Feminino & $13(3,9)$ & $1,8-5,9$ & $8(7,5)$ & $1,8-11,3$ & \\
\hline Ambos & $11(3,3)$ & $1,4-5,2$ & $4(3,7)$ & $0,1-7,4$ & \\
\hline \multicolumn{6}{|l|}{ Conhecido da vítima } \\
\hline Sim & $233(63,1)$ & $58,2-68,1$ & $92(76,7)$ & $69,0-84,3$ & 0,006 \\
\hline Não & $136(36,9)$ & $31,9-41,8$ & $28(23,3)$ & $15,7-31,0$ & \\
\hline \multicolumn{6}{|l|}{ Uso de álcool ${ }^{*}$} \\
\hline Não & $142(66,1)$ & $59,7-72,4$ & $52(76,5)$ & $66,1-86,8$ & 0,107 \\
\hline Sim & $73(34,0)$ & $27,6-40,3$ & $16(23,5)$ & $13,2-33,9$ & \\
\hline \multicolumn{6}{|c|}{ Número de envolvidos * } \\
\hline 1 & $277(85,0)$ & $81,1-88,9$ & $92(86,0)$ & $79,3-92,7$ & 0,798 \\
\hline 2 ou mais & $49(15,0)$ & $11,1-18,9$ & $15(14,0)$ & $7,33-20,7$ & \\
\hline
\end{tabular}


cídio; cinco (1,3\%) desenvolveram transtorno mental; transtorno do comportamento em 90 indivíduos (22,4\%); e transtorno do estresse póstraumático em 77 deles (20,0\%). Essas alterações foram mais prevalentes nas vítimas do sexo masculino e estatisticamente significantes em ambos os sexos.

A obrigatoriedade da notificação de qualquer episódio suspeito ou comprovado de violência aos conselhos tutelares ocorreu em 90,5\% dos casos. Vinte casos $(4,4 \%)$ foram encaminhados à Vara da Infância e Juventude; 36 deles (7,9\%) ao Programa Sentinela; e $26(5,7 \%)$ e $6(1,3 \%)$, respectivamente, à Delegacia de Proteção e ao Ministério Público.

Sete crianças/adolescentes (1,5\%) foram afastadas de suas famílias, sendo acolhidas em uma Casa Abrigo. A necessidade da avaliação por médico perito do IML deu-se em 39,4\% das notificações (183 casos).

\section{Discussão}

Pela primeira vez, fez-se uma avaliação pormenorizada dos dados do estado de Santa Catarina sobre o assunto, com a caracterização do perfil da vítima e de seu agressor.

Com dados coletados em ambiente onde, simultaneamente, ocorreram as notificações e a assistência às vítimas, foi possível fazer a checagem das informações em prontuários médicos, esclarecer dúvidas acerca do preenchimento, eliminar duplicidade e realizar análises inferenciais e de associação.

Apesar de a Ficha de Notificação não ter sido atualizada em 2009 - quando a legislação brasileira mudou o conceito da tipificação do abuso foi possível neste estudo avaliar os tipos de abuso de forma a contemplar conceitos antigos e atuais.

No Brasil, o fenômeno da violência tem mobilizado diferentes áreas do conhecimento, para estabelecer de parcerias que busquem fomentar estratégias de prevenção e intervenção, no enfrentamento do problema ${ }^{25}$. Essa prática visa assegurar o cumprimento de princípios legalmente

Tabela 3. Tipologia dos casos de ASI ( $n=489$ ), segundo o sexo da vítima, notificados pelo HIJG (SINAN), SC, 2008-2014.

\begin{tabular}{|c|c|c|c|c|c|}
\hline \multirow{2}{*}{ Variáveis } & \multicolumn{2}{|c|}{ Feminino } & \multicolumn{2}{|c|}{ Masculino } & \multirow[t]{2}{*}{ p-valor } \\
\hline & n (\%) & IC95\% & n (\%) & IC95\% & \\
\hline $\mathrm{n}$ & $369(100,0)$ & - & $120(100,0)$ & - & \\
\hline Assédio sexual ${ }^{\star}$ & & & & & 0,003 \\
\hline Sim & $129(42,6)$ & $37,0-48,2$ & $26(25,7)$ & $17,1-34,4$ & \\
\hline Não & $174(57,4)$ & $51,8-63,0$ & $75(74,3)$ & $65,6-82,9$ & \\
\hline \multicolumn{6}{|l|}{ Estupro $\dagger$} \\
\hline Sim & $232(62,9)$ & $57,9-67,8$ & $34(28,3)$ & $20,2-36,5$ & 0,079 \\
\hline Não & $137(37,1)$ & $32,2-42,1$ & $86(71,7)$ & $63,5-79,8$ & \\
\hline \multicolumn{6}{|l|}{ Penetração* } \\
\hline Sim & $115(56,1)$ & $49,2-62,9$ & $58(72,5)$ & $62,5-82,5$ & 0,011 \\
\hline Não & $90(43,9)$ & $37,1-50,8$ & $22(27,5)$ & $17,5-37,5$ & \\
\hline \multicolumn{6}{|c|}{ Tipo de Penetração* } \\
\hline Anal & & & & & $<0,001$ \\
\hline Sim & $38(16,4)$ & $11,8-21,6$ & $55(69,2)$ & $59,3-80,0$ & \\
\hline Não & $189(83,3)$ & $78,7-88,4$ & $24(30,4)$ & $20,0-40,7$ & \\
\hline Oral & & & & & 0,012 \\
\hline Sim & $19(8,8)$ & $5,0-12,5$ & $14(19,7)$ & $10,2-29,2$ & \\
\hline Não & $198(91,2)$ & $87,5-95,0$ & $57(80,3)$ & $70,8-89,8$ & \\
\hline \multicolumn{6}{|l|}{ Vaginal } \\
\hline Sim & $128(59,0)$ & $52,4-65,6$ & NA & - & \\
\hline Não & $89(41,0)$ & $34,4-47,6$ & & & \\
\hline
\end{tabular}

IC95\% = intervalo de confiança de 95\%; a Teste qui quadrado; ${ }^{\star}$ Dados sem informação de todos os registros; NA: não aplicável. $\dagger$ Associação de Atentado Violento ao Pudor e Estupro. ASI: Abuso sexual infantil. HIJG: Hospital Infantil Joana de Gusmão. SINAN: Sistema de Informação de Agravos de Notificação. 
Tabela 4. Descrição dos procedimentos realizados $(n=435)$ segundo sexo da vítima de ASI, notificados pelo HIJG (SINAN), SC, $2008-2014$.

\begin{tabular}{|c|c|c|c|c|c|}
\hline \multirow{2}{*}{ Variáveis } & \multicolumn{2}{|c|}{ Feminino } & \multicolumn{2}{|c|}{ Masculino } & \multirow[t]{2}{*}{ p-valor ${ }^{\mathrm{a}}$} \\
\hline & n (\%) & IC95\% & n (\%) & IC95\% & \\
\hline $\mathrm{n}$ & $369(100,0)$ & - & $120(100,0)$ & - & \\
\hline Profilaxia IST ${ }^{\star}$ & & & & & 0,069 \\
\hline Sim & $99(30,7)$ & $25,6-35,7$ & $24(21,6)$ & $13,8-29,4$ & \\
\hline Não & $224(69,6)$ & $64,3-74,4$ & $87(78,4)$ & $70,6-86,2$ & \\
\hline Profilaxia HIV* & & & & & 0,116 \\
\hline Sim & $94(29,1)$ & $24,1-34,1$ & $24(21,4)$ & $13,7-29,1$ & \\
\hline Não & $229(70,9)$ & $65,9-75,9$ & $88(78,6)$ & $70,9-86,3$ & \\
\hline Profilaxia $\mathrm{HBV}^{\star}$ & & & & & 0,318 \\
\hline Sim & $71(22,5)$ & $17,9-27,2$ & $20(18,0)$ & $10,8-25,3$ & \\
\hline Não & $244(77,5)$ & $72,8-82,1$ & $91(82,0)$ & $74,7-89,2$ & \\
\hline Coleta de sangue ${ }^{*}$ & & & & & 0,069 \\
\hline Sim & $167(52,5)$ & $47,0-58,0$ & $49(42,6)$ & $33,4-51,8$ & \\
\hline Não & $151(47,5)$ & $42,0-53,0$ & $66(57,4)$ & $48,2-66,6$ & \\
\hline Coleta de sêmen* & & & & & 0,901 \\
\hline Sim & $33(10,7)$ & $7,2-14,1$ & $12(11,1)$ & $5,1-17,1$ & \\
\hline Não & $276(89,3)$ & $85,6-92,8$ & $96(88,9)$ & $82,9-94,9$ & \\
\hline Coleta de secreção vaginal ${ }^{\star}$ & & & & & NA \\
\hline Sim & $70(24,7)$ & $19,6-29,7$ & NA & - & \\
\hline Não & $214(75,3)$ & $70,3-80,4$ & NA & & \\
\hline \multicolumn{6}{|l|}{ Contracepção de emergência* } \\
\hline Sim & $48(16,7)$ & $12,3-21,0$ & NA & - & NA \\
\hline Não & $240(83,3)$ & $79,0-87,7$ & NA & & \\
\hline \multicolumn{6}{|l|}{ Aborto Previsto em Lei* } \\
\hline Sim & $5(3,5)$ & $0,4-6,5$ & NA & - & NA \\
\hline Não & $138(96,5)$ & $93,5-99,6$ & NA & & \\
\hline
\end{tabular}

assegurados no ECA quanto às políticas e programas voltados à violência social e interpessoal contra crianças e adolescentes ${ }^{1,3}$.

Nesse país é possível, desde 1997, a utilização de uma ferramenta social de denuncia denominada Disque Denúncia, popularmente conhecido como Disque $100^{26}$.

Foi observado que, apesar de o módulo de violência ter sido inserido no SINAN em 2008, o número de notificações permaneceu estável até 2010. A implementação de políticas de capacitação de pessoal na área de violência e divulgação da ferramenta eletrônica, pode ter dado maior visibilidade a ela, ou o seu melhor uso, ou ambos, refletindo assim no aumento do número das notificações.

A prevalência das notificações no sexo feminino corrobora a literatura, que aponta a maior frequência de ASI em meninas ${ }^{7,27-29}$.
Assim como em trabalhos anteriores, este estudo evidenciou que, ao se associar idade e sexo, há uma tendência de os meninos serem abusados em idades mais precoces ${ }^{7,9}$, possivelmente por não possuírem o desenvolvimento físico para oferecer resistência ${ }^{30-32}$. Já as meninas sofrem abuso em idade mais tardia ${ }^{33-35}$, o que foi observado também neste estudo.

O fato de a maioria das notificações corresponder a vítimas do sexo feminino pode ser, em parte, justificada por subnotificações de ASI no sexo masculino, decorrentes do preconceito que surge quanto à identidade sexual após o menino ser abusado ${ }^{7}$.

Uma questão debatida por Araújo que justifica também o maior número de casos no sexo feminino é que o ASI envolve duas desigualdades básicas: de gênero e geração. Nos seus relatos de casos a questão de gênero e o fator econômico 
foram questões destacadas: A dominação masculina e a submissão feminina, cristalizadas, naturalizam a produção e repetição de comportamentos abusivos por parte do homem detentor do poder de pai, provedor material e chefe da família. Ao se colocarem na condição de inferioridade, as próprias mulheres delegam poderes a seus maridos, companheiros e pais. E é nesse lugar que eles reproduzem comportamentos abusivos ${ }^{36}$.

A maior ocorrência de abuso ocorreu entre as crianças menores de 12 anos de idade (67,7\%). Em metanálise conduzida pela OMS, foi observado que a idade do acontecimento do abuso variou consideravelmente entre os 22 estudos; entretanto, seu início foi consistentemente mais prevalente na idade de 5-14 anos, tanto para o sexo masculino como para o feminino ${ }^{3}$. Aded et al. ${ }^{30}$ inferiram que, para as vítimas em uma faixa etária mais elevada, poderia haver alguma dificuldade em relatar queixas de abuso sexual, devido ao possível constrangimento resultante e à repercussão familiar e social ${ }^{35}$. Também em algumas sociedades a prática de atividade sexual em idades superiores a doze anos pode não ser considerada abuso ${ }^{35}$.

Os portadores de deficiências ou transtornos, físicos ou mentais, estão em maior risco e são mais vulneráveis a sofrerem violência de todos os tipos, inclusive a sexual ${ }^{35}$. Mesmo não havendo diferença significativa avaliada pelo teste de qui-quadrado, constata-se que 27 vítimas (5,5\%) possuíam alguma deficiência, podendo ser ela física ou mental, transtorno ou síndrome. Aventa-se a hipótese de que a própria limitação física/ mental seja um determinante do baixo índice de denúncia, devido ao seu alto grau de dependência física e sensorial, e porque muitas vezes os sinais e sintomas clínicos do abuso são ignorados por serem considerados decorrentes da doença principal $^{37}$.

A população da região Sul do país é predominantemente de cor branca ${ }^{21,38}$, sendo portanto esperado que a maioria das vítimas sejam brancas, corroborando estudo realizado no Rio Grande do $\mathrm{Sul}^{39}$ e diferindo do levantamento realizado por Silva et al. ${ }^{34}$, em Recife, onde a maioria das vítimas eram pardas. A pequena prevalência da raça indígena no estudo, um caso de uma menina índia residente no município de José Boiteux, onde existe uma reserva indígena, também foi observada por Zanatta et al. ${ }^{39}$.

O maior número de notificações de ASI em população urbana desse estudo pode ser atribuída à maior concentração populacional nessa área ou à dificuldade de acesso de comunidades rurais aos locais de referência ${ }^{40}$. Pode também decorrer de questões culturais características de zonas rurais que dificultam a revelação do abuso ${ }^{37,41}$. Dessas características, embora não exclusivas da população rural, podemos citar a tendência de valorizar a privacidade da vida familiar, ou até a reprodução de uma cultura familiar onde a violência e o abuso sexual acontecem e se mantêm protegidos pela lei do silêncio ${ }^{36}$. Há ainda a possibilidade do não confrontamento com o discurso dos pais para evitar o conflito intrafamiliar ${ }^{42}$.

$\mathrm{O}$ registro de ocorrências de ASI de outros municípios além de Florianópolis deve-se ao fato de o hospital onde as notificações foram realizadas ser referência regional nos atendimentos pediátricos. Chama a atenção municípios pequenos terem encaminhado as vítimas para atendimento a esse hospital sem a prévia realização da notificação na própria unidade de saúde de sua cidade. Aventa-se a possibilidade de temor do profissional que fez o diagnóstico em sofrer retaliação pela comunidade ou mesmo pelos pais das vítimas ${ }^{40}$. Já Gonçalves e Ferreira não apontam esse como um fator relevante para a não notificação. Para essas autoras, são de maior impacto as ameaças dos agressores aos familiares que tomam a iniciativa de procurar o setor saúde ${ }^{42}$. Pode também ocorrer receio da família em procurar ajuda em serviços de seu local de moradia, por se tratar de agravo que gera preconceito e estigmatização ${ }^{37}$. Isso mostra o quão importante é assegurar o sigilo das informações por parte de toda a equipe de profissionais que atendem essas vítimas ${ }^{35}$.

Outras justificativas para o grande número de notificações em Florianópolis devem-se ao fato desse município ser mais populoso ${ }^{43}$, contar com uma rede de atenção à saúde mais organizada e com protocolo de atendimento às pessoas em situação de violência sexual implantado há 15 $\operatorname{anos}^{44}$.

Merecem destaque os casos ocorridos em outras unidades federativas e notificados em Florianópolis. Sabe-se que, em algumas situações, as crianças e adolescentes são enviados para morar com parentes quando da descoberta do abuso ou há a migração da família para outra localidade. Somente após a mudança de ambiente é que ocorre a revelação do abuso ${ }^{45}$.

A casa da vítima ou do autor como local predominante de abuso concorda com a literatu$\mathrm{ra}^{7,27,29,32,45}$, o que nos alerta para a constatação de que a tradicional "barreira privada" entre as esferas doméstica e pública tem inibido a evolução de políticas e instrumentos legais, para prevenir a violência intrafamiliar e a prestação de serviços 
para aqueles afetados por ela ${ }^{1,42}$. Segundo Pfeiffer e Salvagni ${ }^{37}$, trabalha-se com um fenômeno que é encoberto por segredo, por um "muro de silêncio", do qual fazem parte os familiares, vizinhos e algumas vezes os profissionais que atendem as crianças vítimas de violência.

Resultados de estudos nacionais e internacionais apontam que o principal autor do abuso é conhecido das vítimas e de suas famílias ${ }^{7,27-28,45}$. Isso também foi evidenciado neste estudo, ressaltando-se que o autor do abuso mantinha relações estreitas com suas vítimas.

Em 2006, nos EUA, em casos comprovados, $26,0 \%$ dos autores de ASI foram os pais ${ }^{46}$. Na Suíça, em 2013, Maier et al. ${ }^{28}$ identificaram o pai como autor mais frequente. Para estes autores, crianças são mais frequentemente ameaçadas e vitimizadas por membros de sua própria família, na seguinte ordem decrescente de incidência: pais, irmãos, mães e outros cuidadores.

No presente estudo o pai como autor do abuso ocorreu em 17,5\% dos casos. Prevalência de $21,7 \%$ de pai como o autor do abuso foi encontrada por Drezett et al. ${ }^{45}$ e por Baptista et al. ${ }^{46}$ apontaram o vínculo do autor do abuso com a vítima na seguinte ordem: pai, padrasto, tio, avô, primo. Já Gawryszewski et al. ${ }^{7}$, em São Paulo, encontraram em 43,8\% dos casos os responsáveis pelas vítimas como autores da agressão.

A maior parte dos autores do abuso era homem, resultado semelhante a diversos levantamentos ${ }^{7,29,32,36}$. No presente estudo as autoras femininas vitimizaram ambos os sexos, com uma taxa de 4,7\%, diferentemente do observado por Cartón Duarte et al. ${ }^{27}$, em que autoras do sexo feminino só fizeram vítimas do mesmo sexo. A prevalência de autoria feminina encontrada por Maier et al. ${ }^{28}$ foi de 4,5\% e de Martins e Melo Jorge $^{32}$ foi de 2,1\%. Autores de ASI do sexo feminino, segundo Linsay et al. ${ }^{47}$, tiveram maiores taxas de abuso infantil prévio.

Geralmente o autor age sozinho. A prevalência de mais de uma pessoa no crime de abuso ocorreu em 14,8\% neste estudo, semelhante à descrita por Drezett et al. ${ }^{45}$, que foi de 10,0\%.

Com relação ao tipo de abuso, se utilizada a definição de atentado violento ao pudor existente antes da alteração da legislação de 2009 , observase a prevalência de $40,7 \%$, semelhante ao descrito por Maier et al. ${ }^{28}$, em que o abuso sem contato ou com contato mas sem penetração apresentou prevalência entre 36,0 e $42,0 \%$. No estudo de Cartón Duarte et al. ${ }^{27}$ essa taxa foi de $63,0 \%$.

Gilbert et al. $^{48}$, em 2009, relataram que, durante a infância, entre 5,0 a 10,0\% das meninas e 5,0\% dos meninos são expostos a ASI com penetração. Mohler-Kuo et al. ${ }^{29}$ descreveram uma prevalência de 2,5\% de ASI com contato e com penetração nas vítimas do sexo feminino e de $0,6 \%$ no sexo masculino. Essa prevalência é bem inferior e contrária à encontrada neste estudo onde, dos 285 casos avaliados neste quesito, em $56,1 \%$ das vítimas do sexo feminino e $72,5 \%$ das do sexo masculino houve algum tipo de penetração. Essa discrepância pode ser decorrente de o estudo ter sido realizado na Suíça e do próprio desenho deste - estudos de base populacional e estudos de casos produzem resultados bem diversos, devendo-se atentar para as diferenças metodológicas existentes. Portanto, como alertam Collin-Vézina et al. $^{49}$, os resultados de estudos nessa área não podem ser extrapolados para os outros países sem serem consideradas as diferenças entre as culturas e os contextos sociais.

A profilaxia das ISTs e gravidez está indicada nos casos em que a vítima chega ao atendimento até 72 horas após o abuso e havendo contato com secreções $^{42}$. A realização de testes sorológicos diagnósticos antes da profilaxia é preconizada internacionalmente ${ }^{3}$ pois permite a identificação de ISTs principalmente em crianças abaixo de 10 anos de idade. Cabe ressaltar que nos países desenvolvidos há disponibilidade de testes rápidos fidedignos, por meio da reação de cadeia da polimerase (PCR), não preconizados rotineiramente no Brasil, o que talvez explique as baixas taxas de realização das profilaxias neste estudo ${ }^{41}$.

A rotina dos atendimentos realizados nos casos analisados seguiu o Protocolo da Rede de Atenção Integral às Pessoas em Situação de Violência Sexual (RAIVS). Esse protocolo utiliza os testes sorológicos para investigação dos agravos infecciosos. Pelo fato de os resultados desses testes não serem imediatos, a vítima, quando atendida dentro das primeiras 72 horas e tendo indicação de uso de medicamentos, recebe antibióticos para profilaxia das ISTs bacterianas e dois antirretrovirais, além da contracepção de emergência ${ }^{43}$. Os casos de não realização de profilaxias medicamentosas podem corresponder ao não atendimento ao que é preconizado no Protocolo RAIVS, visto que muitos casos eram apenas suspeitos, não ter havido contato com secreção e ao fato de a notificação ter ocorrido após 72h.

Já os procedimentos preconizados para a profilaxia da Hepatite B foram menos realizados quando comparados com os de ISTs e HIV. Isso pode ser atribuído à possibilidade de a vítima possuir o esquema vacinal completo, conferido na caderneta de saúde da criança ou adolescen- 
te, durante o atendimento. Como proporcionalmente o número de atendimento às vítimas do sexo feminino foi superior ao masculino, o maior número de procedimentos prestados ocorreu ao sexo feminino, apesar das diferenças estatísticas não terem sido significantes.

O encaminhamento obrigatório a instituições de proteção, como Conselho Tutelar visto por Gawryszewski et al. ${ }^{7}$ foi de 70,7\%. Apesar da obrigatoriedade da notificação de qualquer caso suspeito ou comprovado de violência aos conselhos tutelares desde $1990^{50}$, observamos que ela não ocorreu em sua totalidade. Flahertyet al. ${ }^{51}$ referem que alguns pediatras são relutantes em envolver agências de proteção, mesmo que exista um forte indício de abuso. Esses autores citam como motivos dessa relutância a desconfiança nessas agências, o temor de que a criança seja retirada do convívio familiar, implicando situação de duplo efeito, uma vez que cria um outro dano ${ }^{52}$, bem como a crença de que sozinhos possam resolver todo o problema ${ }^{49}$.

Observa-se que, ao ser revelado o abuso, o sistema familiar pode ser desfeito, com a possibilidade de as crianças serem retiradas de casa ${ }^{14}$. No presente estudo constatou-se essa situação em sete casos, menos do que relatado por Pereda et al. ${ }^{2}$ em sua publicação no ano de 2006.

Agravos impactantes como ASI causam inúmeras sequelas que repercutem por toda a vida. A Ficha de Notificação do SINAN permitiu a avaliação de algumas delas. No período de sete anos que abrange este estudo, as taxas de gravidez, de abortamento previsto em lei e de ISTs foram respectivamente $1,0 \%, 3,5 \%$ e $3,4 \%$. Segundo a Academia Americana de Pediatria ${ }^{53}$, aproximadamente 5,0\% das crianças abusadas sexualmente contraem uma IST de seus vitimizadores. Hillis et al. ${ }^{54}$ notaram a existência de efeitos, de pequenos a moderados, do ASI no aumento das taxas de gravidez na adolescência, de aborto e do risco de contrair ISTs.

A tentativa de suicídio observada no presente estudo é diferente do encontrado na coorte de base populacional de Fergusson et al. ${ }^{9}$, na Nova Zelândia, que mostrou uma prevalência de 11,0 - $21,0 \%$ de tentativas de suicídio nos adultos jovens e adolescentes que experimentaram violência física severa e abuso sexual com penetração, contra $1,0-3,0 \%$ dos controles. É possível conjecturar que, se houvesse dados de seguimento das vítimas, a repercussão poderia ser melhor avaliada por um profissional especializado e a prevalência seria maior.

Cummings et al. ${ }^{14}$ encontraram uma prevalência de TEPT variando de $37,0 \%$ a $53,0 \%$ entre crianças abusadas; Chen et al. ${ }^{11}$ encontraram a prevalência de $23 \%$ nas vítimas pré-adolescentes. No instrumento de coleta de dados utilizado consta a alternativa de TEPT, que apareceu neste estudo em 20,0\% dos casos. Esse dado pode ser analisado criticamente, visto que para se estabelecer o diagnóstico TEPT são necessários alguns quesitos, como um tempo mínimo de sintomas de três meses ${ }^{55}$, o que é impossível nos casos de ASI agudo, com menos de 72 horas de evolução. Uma sugestão alternativa à "consequência TEPT", na ficha, seria a presença da opção Transtorno do Estresse Agudo.

Pode-se admitir como potenciais limitações deste estudo as relativas ao uso de dados secundários, minimizadas pela conferência da sua veracidade nos prontuários médicos das vítimas que seguiram acompanhamento na instituição. As subnotificações, que podem ser atribuídas tanto à negação da família em procurar auxílio, como por simular outras situações para justificar as lesões apresentadas pelas vítimas, o que nem sempre é identificado como abuso sexual pelo profissional que realiza o atendimento ${ }^{30}$.

Alguns indicadores relevantes para ASI não foram incluídos na análise, por utilizarem uma ficha padronizada nacionalmente para a notificação dos casos de violência sexual, com dados pré-determinados.

É fundamental tornar mais acessível o instrutivo de preenchimento das notificações do SINAN, pois ao analisar o banco de dados questionamos se quem o preencheu estava a par das definições, assim como o preenchimento incompleto compromete a análise de algumas variáveis $^{12}$. É importante realizar capacitações multidisciplinares mais frequentes sobre o tema ASI e sobre o instrumento de notificação - em todas as regiões do estado - e fazer busca ativa nos casos notificados e que não retornam ao seguimento ambulatorial $^{56}$.

Ao se deparar com situações de violência contra a criança, o profissional mobiliza emoções e sentimentos que nem sempre permite a tomada de decisões racionais, fato que pode dificultar o preenchimento adequado da ficha de notificação. Ressalta-se aí a importância do trabalho multidisciplinar e inter setorial que envolva ações integradas de cuidado e atenção à saúde, punição do agressor e proteção às crianças e famílias submetidas a situações de violência e de abuso sexual ${ }^{36}$.

Há que se pensar também que o preenchimento incompleto pode decorrer do local onde habitualmente este é realizado: setor de emergência dos hospitais públicos, com grande demanda 
de pacientes, longas filas de espera e o tempo requerido para o seu completo preenchimento.

\section{Conclusões}

No período analisado de sete anos, das 489 notificações de ASI, 369 correspondiam a vítimas do sexo feminino e 120 do sexo masculino. A faixa etária mais acometida foi de 10 a 15 anos nas meninas e, de 2 a 6 anos nos meninos. A residência foi o local de ocorrência mais frequente e os perpetradores eram na maioria homens que, em $66,5 \%$ dos casos, eram conhecidos das vítimas.
A recorrência do abuso foi mais frequente nas vítimas do sexo masculino. Em 3,5\% dos casos houve interrupção legal da gestação e 1,0\% levou adiante a gravidez.

As características de ASI foram muito semelhantes às de diversos locais do Brasil, mostrando ser possível ações coordenadas nacionalmente para prevenir esse agravo.

Trata-se de um tema extremamente importante na área social com grande repercussão na vida futura dos envolvidos, especialmente das crianças, e por isso urgem ações que controlem esse grave problema brasileiro de Saúde Pública.

\section{Colaboradores}

VB Platt contribuiu substancialmente para a concepção, o planejamento, a análise, a interpretação dos dados, a elaboração do rascunho, a revisão crítica do trabalho e a aprovação da versão final do trabalho. IC Back colaborou na concepção, na análise e interpretação dos dados, na revisão crítica do conteúdo e na aprovação final do trabalho. DB Hauschild contribuiu no planejamento e na análise e interpretação dos dados. JM Guedert colaborou na interpretação dos dados e na revisão crítica do conteúdo.

\section{Agradecimentos}

À Dra Eliane Vieira Araújo - Núcleo de Epidemiologia do Hospital Infantil Joana de Gusmão. Às crianças em situação de violência, por me motivarem a tornar públicos esses dados. 


\section{Referências}

1. Kempe CH. Sexual abuse, another hidden pediatric problem: the 1977 C. Anderson Aldrich lecture. Pediatrics 1978; 62(3):382-389.

2. Pereda N, Guilera G, Forns M, Gómez-Benito J. The international epidemiology of child sexual abuse: a continuation of Finkelhor (1994). Child Abuse Negl 2009; 33(6):331-342.

3. Andrews G, Corry J, Slade T, Issakidis C, Swanston H. Child sexual abuse. In: Ezzati M, Lopez AD, Rodgers A, Murray CJL, editors. Comparative quantification of health risks: global and regional burden of disease attributable to selected major risk factors. Geneve: WHO; 2004. p. 1851-1940.

4. Laaksonen T, Sariola H, Johansson A, Jern P, Varjonen $\mathrm{M}$, von der Pahlen B, et al. Changes in the prevalence of child sexual abuse, its risk factors, and their associations as a function of age cohort in a finnish population sample. Child Abuse Negl 2011; 35(7):480-490.

5. Aded NLO, Oliveira SF, Dalcin BLGS, Moraes TM, Cavalcanti MT. Children and adolescents victimized by sexual abuse in the city of Rio de Janeiro: an appraisal of cases. J Forensic Leg Med 2007; 14(4):216-220.

6. De Lorenzi DRS, Pontalti L, Flech RM. Maus tratos na infância e adolescência: análise de 100 casos. Rev Cient AMECS 2001; 10(1):1-6.

7. Gawryszewski VP, Valencich DM, Carnevalle CV, Marcopito LF. Child and adolescent abuse in the state of São Paulo, Brazil, 2009. Rev Assoc Med Bras 2012; 58(6):659-665.

8. Machado HB, Lueneberg CF, Régis EI, Nunes MPP. Abuso sexual: diagnóstico de casos notificados no município de Itajaí/SC, no período de 1999 a 2003, como instrumento para a intervenção com famílias que vivenciam situações de violência. Texto Contexto Enfem 2005; 14(n. esp.):54-63.

9. Fergusson DM, Boden JM, Horwood LJ. Exposure to childhood sexual and physical abuse and adjustment in early adulthood. Child Abuse Negl 2008; 32(6):607-619.

10. Committee on Child Abuse and Neglect (COCAN). Protecting children from sexual abuse by health care providers. Pediatrics 2011; 128(2):407-426.

11. Chen LP, Murad MH, Paras ML, Colbenson KM, Sattler AL, Goranson EN, Elamin MB, Seime RJ, Shinozaki G, Prokop LJ, Zirakzadeh A. Sexual abuse and lifetime diagnosis of psyquiatric disorders: systematic review and meta-analysis. Mayo Clin Proc 2010; 85(7):618629.

12. Salter D, McMillan D, Richards M, Talbot T, Hodges J, Bentovim A, Hastings R, Stevenson J, Skuse D. Development of sexually abusive behaviour in sexually victimised males: a longitudinal study. Lancet 2003; 361(9356):471-476.

13. Modelli ME, Galvão MF, Pratesi R. Child sexual abuse. Forensic Sci Int 2012; 217(1-3):1-4.

14. Cummings M, Berkowitz SJ, Scribano PV. Treatment of childhood sexual abuse: an updated review. Curr Psychiatry Rep 2012; 14(6):599-607.

15. Jenny C, Crawford-Jakubiak JE. The evaluation of children in the primary care setting when sexual abuse is suspected. Pediatrics 2013; 132(2):e558-567.
16. Wilson DR, Vidal B, Wilson WA, Salyer SL. Overcoming sequelae of childhood sexual abuse with stress management. J Psychiatr Ment Health Nurs 2012; 19(7):587-593.

17. Paraventi F, Claudino AM, Morgan CM, Mari JJ. Estudo de caso controle para avaliar o impacto do abuso sexual infantil nos transtornos alimentares. Rev Psiq Clin 2011; 38(6):222-226.

18. Pérez-Fuentes G, Olfson M, Villegas L, Morcillo C, Wang S, Blanco C. Prevalence and correlates of child sexual abuse: a national study. Compr Psychiatry 2013; 54(1):16-27.

19. Brasil. Ministério da Saúde (MS). Instrutivo de notificação/investigação de violência doméstica, sexual e/ ou outras violências. Brasília: MS; 2009.

20. Marcondes E, Vaz FAC, Ramos JLA. Pediatria básica: Tomo III - Pediatria clínica especializada. São Paulo: Sarvier; 2004.

21. Instituto Brasileiro de Geografia e Estatística (IBGE). População. Indicadores sociais mínimos. Rio de Janeiro: IBGE; 2014.

22. Instituto Brasileiro de Geografia e Estatística (IBGE). Cidades@.Santa Catarina. Rio de Janeiro: IBGE; 2014.

23. Brasil. Lei no 12.015, de 07 de agosto de 2009. Altera o Título VI da Parte Especial do Decreto-Lei no 2.848, de 7 de dezembro de 1940 - Código Penal, e o art. 10 da Lei no 8.072, de 25 de julho de 1990, que dispõe sobre os crimes hediondos, nos termos do inciso XLIII do art. 5o da Constituição Federal e revoga a Lei no 2.252, de lo de julho de 1954, que trata de corrupção de menores. Diário Oficial da União 2009; 10 ago.

24. Brasil. Decreto-Lei no 2.848, de 7 de dezembro de 1940. Código Penal. Diário Oficial da União 1940; $31 \mathrm{dez}$.

25. Minayo MCS. O significado social e para a saúde da violência contra crianças e adolescentes. In: Westphal MF, organizador. Violência e criança. São Paulo: Ed. USP; 2002. p. 95-11.

26. Disque Direitos Humanos - Disque 100 - Disque Denúncia. [acessado 2015 Jun 5]. Disponível em: http://www.crianca.mppr.mp.br/modules/conteudo/ conteudo.php? conteudo $=3$

27. Cartón Duarte J, Cortés Arboleda MR, Cantón-Cortés D. Variables associated with the nature os sexual abuse to minors. Span J Psychol 2012; 15(2):571-581.

28. Maier T, Mohler-Kuo M, Landolt MA, Schnyder U, Jud A. The tip of the iceberg. Incidence of disclosed cases of child sexual abuse in Switzerland: results from a nationwide agency survey. Int J Public Health 2013; 58(6):875-883.

29. Mohler-Kuo M, Landolt MA, Maier T, Meidert U, Schönbucher V, Schnyder U. Child sexual abuse revisited: a population-based cross-sectional study among swiss adolescents. I Adolesc Health 2014; 54(3):304-311.

30. Aded NLO, Dalcin BLGS, Cavalcanti MT. Estudo da incidência de abuso sexual contra crianças no Rio de Janeiro, Brasil. Cad Saude Publica 2007; 23(8):19711975. 
31. Hohendorff JV, Habigzang LF, Koller SH. Violência sexual contra meninos: dados epidemiológicos, características e consequências. Psicol USP 2012; 23(2):395-415.

32. Martins CBG, Melo Jorge MHP. Abuso sexual na infância e adolescência: perfil das vítimas e agressores em município do Sul do Brasil. Texto Contexto Enferm 2010; 19(2):246-255.

33. Bassani DG, Palazzo LS, Beria JU, Gigante LP, Figueiredo ACL, Aerts DRGC. Child sexual abuse in southern Brazil and associated factors: a populationbased study. BMC Public Health 2009; 9:133.

34. Silva MCM, Brito AM, Araújo AL, Abath MB. Caracterização dos casos de violência física, psicológica, sexual e negligências notificados em Recife, Pernambuco, 2012. Epidemiol Serv Saúde 2013; 22(3):403-412.

35. Furniss T. Abuso Sexual da criança: uma abordagem multidisciplinar: manejo, terapia \& intervenção legal integrados. Porto Alegre: Artes Médicas; 1993.

36. Araújo MF. Violência e abuso sexual na família. Psicologia em Estudo 2002; 7(2):3-11.

37. Pfeiffer L, Salvagni EP. Visão atual do abuso sexual na infância e adolescência. J Pediatr (Rio J) 2005; 81(5-Supl.):s197-s204.

38. Instituto Brasileiro de Geografia e Estatística (IBGE). População: indicadores sociais mínimos. Rio de Janeiro: IBGE; 2014.

39. Zanatta EA, Dal Pai D, Resta DG, Argenta C, Motta MGC. Caracterização das notificações de violência contra adolescentes. Enferm foco 2012; 3(4):165-168.

40. Pires JM, Goldani MZ, Vieira EM, Nava TR, Feldens L, Castilhos K, Simas V, Franzon NS. Barreiras, para a notificação pelo pediatra, de maus tratos infantis. Rev Bras Saúde Mater Infant 2005; 5(1):103-108.

41. Kliegman RM, Behrman RE, Jenson HB, Stanton BF. Nelson textbook of pediatrics [e-book]. $19^{\text {th }}$ ed. Philadelphia: Saunders Elsevie; 2011.

42. Gonçalves HS, Ferreira AL. A notificação da violência intrafamiliar contra crianças e adolescentes por profissionais de saúde. Cad Saude Publica 2002; 18(1):315-319.

43. Instituto Brasileiro de Geografia e Estatística (IBGE). Cidades@. Santa Catarina. Rio de Janeiro: IBGE; 2014.

44. Prefeitura Municipal de Florianópolis, Secretaria Municipal de Saúde, Programa Saúde da Mulher. Protocolo de atenção as vítimas de violência sexual do município de Florianópolis. Tubarão: Copiart; 2010.

45. Drezett J, Caballero M, Juliano Y, Prieto ET, Marques JA, Fernandes CE. Estudo de mecanismos e fatores relacionados com o abuso sexual em crianças e adolescentes do sexo feminino. J Pediatric (Rio J) 2001; 77(5):413-419.

46. Baptista RS, França ISX, Costa CMP, Brito VRS. Caracterização do abuso sexual em crianças e adolescentes notificado em um Programa Sentinela. Acta Paul Enferm 2008; 21(4):602-608.
47. Lindsay W, Steptoe L, Haut F. Brief report: the sexual and physical abuse histories of offenders with intellectual disability. J Intellect Disabil Res 2012; 56(3):326-331.

48. Gilbert R, Widom CS, Browne K, Fergusson D, Webb E, Janson S. Burden and consequences of child maltreatment in high-income countries. Lancet 2009; 373(9657):68-81.

49. Collin-Vézina D, Hélie $S$, Trocmé N. Is child sexual abuse declining in Canada? An analysis of child welfare data. Child Abuse Negl 2010; 34(11):807-812.

50. Brasil. Portaria no $1.968 / \mathrm{GM} / \mathrm{MS}$, de 25 de outubro de 2001. Dispõe sobre a notificação, às autoridadescompetentes, de casos de suspeita ou de confirmação de-maus-tratos contra-crianças e adolescentes atendidos nas entidades do Sistema Unido de Saúde. Diário Oficial da União 2001; 26 out.

51. Flaherty EG, Macmillan HL, Committee on Child Abuse and Neglect. Caregiver-fabricated illness in a child: a manifestation of child maltreatment. Pediatrics 2013; 132(3):590-597.

52. Ferreira AL, Schramm FR. Ethical implications of domestic violence against child for the health care professionals. Rev Saude Publica 2000; 34(6):659-665.

53. American Academy of Pediatrics Committee on Infectious Diseases, Kimberlin DW, Brady MT, Jackson MA, SS Long, editors. Red book ${ }^{\circledR} 2009$ - Report of the Committee on Infectious Diseases. $28^{\text {th }}$ ed. Elk Grove Village: American Academy of Pediatrics; 2009. p. 758.

54. Hillis SD, Anda RF, Dube SR, Felitti VJ, Marchbanks PA, Marks JS. The association between adverse childhood experiences and adolescent pregnancy, long-term psychosocial consequences, and fetal death. Pediatrics 2004 [acessado 2014 Jan 15];113(2):320-327.

55. American Psychiatric Association. Diagnostic and statistical manual of mental disorders. $5^{\text {th }}$ ed. Arlington: DSM; 2013.

56. Brasil. Portaria no 485/GM/MS, de 1 de abril de 2014 . Redefine o funcionamento do Serviço de Atenção às Pessoas em Situação de Violência Sexual no âmbito do Sistema Único de Saúde (SUS). Diário Oficial da União 2014; 2 abr.

Artigo apresentado em 25/01/2016

Aprovado em 21/06/2016

Versão final apresentada em 23/06/2016 